ALPHA No 29 Diciembre 2009 (233-249)

ISSN 0716-4254

http://alpha.ulagos.cl

\title{
COMUNIDADES INTERPRETATIVAS. PERSPECTIVAS DE LA HERMENÉUTICA LITERARIA DE STANLEY FISH
}

Interpretative communities. Perspectives on Stanley Fish's literary

hermeneutics

Juan Antonio González de Requena Farré*

Resumen

Este artículo explora una de las nociones más comprensivas de la hermenéutica contemporánea: el concepto de "comunidad interpretativa" que nos recuerda que cada interpretación descansa en el trasfondo de nuestra precomprensión de las prácticas compartidas y de los compromisos institucionales. Por lo mismo, se indaga en los orígenes de la "comunidad interpretativa" — en la hermenéutica fronteriza de Stanley Fish (una hermenéutica postmetafísica y literaria) — para comprender los límites de la koiné hermenéutica y elucidar diferentes interpretaciones de los trasfondos comprensivos comunes, a través de nuestra tradición hermenéutica.

Palabras clave: Comunidades interpretativas, hermenéutica, fundacionalismo, retórica.

Abstract

In this article, we explore one of the most comprehensive notions of our contemporary hermeneutics: the concept of "interpretative community", which reminds us that every interpretation relies on the background of our precomprehension of shared practices and institutional commitments. Thus, we inquire the origins of the "interpretative community" in the border hermeneutics of Stanley Fish (a postmetaphysical and literary hermeneutics), in order to understand the limits of the hermeneutical community, and to elucidate different interpretations of our common comprehensive backgrounds, through our hermeneutical tradition.

Key words: Interpretative communities, hermeneutics, foundationalism, rethoric.

\section{INTRODUCCIÓN. LUGAR DE LA HERMENÉUTICA LITERARIA DE FISH EN LA HERMENÉUTICA CONTEMPORÁNEA}

Sin duda, justo en el momento en que se ha convertido en un lugar común la vigencia de cierta koiné hermenéutica (Vattimo, 1991:55-71) resulta más urgente que nunca preguntarse por el tipo de comunidad cultural que vincula a las muy variopintas teorías de la interpretación. Pero, también, hay que interrogarse acerca de la constitución misma de una comunidad 
interpretativa, toda vez que ella conforma el trasfondo de sentido presupuesto tanto en cualquier comprensión mundana, cuanto en toda reflexión hermenéutica. De ahí nuestra elección de una propuesta como la de Stanley Fish, a la hora de dar cuenta del proyecto y sentido de la koiné hermenéutica. En primer lugar, tratándose de una apuesta interpretativa fronteriza con respecto a la hermenéutica filosófica (internamente vinculada con ella, al asumir la constitución interpretativa de todo sentido, pero desvinculada externamente, por su posición implícitamente neo-pragmatista y postfilosófica) la intervención de Fish permite elucidar tanto los límites irrebasables de la comunidad hermenéutica como su proyecto compartido. En segundo lugar, por haber introducido en las discusiones sobre la interpretación textual el muy fecundo concepto de "comunidad interpretativa”, la propuesta de Fish hace posible explicitar y problematizar las posibles configuraciones del trasfondo de sentido que toda posición hermenéutica presupone (como convivir comprensivo, pertenencia a la tradición, destinación histórico-epocal, involucramiento pragmático, solidaridad, etc.). Así, pues, emprendemos una doble tarea de indagación que nos llevará tanto a revisar el perfil hermenéutico de la apuesta interpretativa de Fish, cuanto a examinar diversas concepciones de la comunidad interpretativa, tal y como han sido propuestas en la tradición hermenéutica.

Ciertamente, saludamos algunos aspectos de la apuesta hermenéutica de Fish: ésta insiste en la radical facticidad contextual de toda comprensión e invita a asumir esa interminable deriva interpretativa en que sólo cabe realizar interpretaciones de las interpretaciones. Sin embargo, sospechamos que el convencionalismo de Fish encubre un intento de clausurar y encuadrar (en nombre de los compromisos profesionales e institucionales de los intérpretes) tanto la apertura de la interpretación como el acontecimiento del sentido. Y es que el convencionalismo retórico de Fish reduce la tarea de interpretación a un ejercicio retórico de persuasión, basado en los compromisos institucionales infranqueables de una comunidad interpretativa. En ese sentido, se corre el riesgo de fetichizar los marcos locales de interpretación institucional, de tal manera que las prácticas interpretativas resulten inmunes frente a cualquier conflicto y contestación de interpretaciones o ante la crítica inmanente de las contradicciones internas a nuestros contextos institucionales. En ese mismo momento, el convencionalismo retórico se convierte en una metafísica invertida que termina consagrando las perspectivas autorreferentes de los marcos institucionales, como si todas fueran localmente defendibles e igualmente imposibles de trascender (Eagleton, 2005:118-124). 
Comunidades interpretativas. Perspectivas de la hermenéutica literaria

\section{EL CONVENCIONALISMO RETÓRICO COMO CONJURACIÓN DEL FUNDA- CIONALISMO Y EL FORMALISMO}

La apuesta interpretativa de Fish tiene como punto de partida un marcado distanciamiento con respecto a toda posición teórica de carácter esencialista y fundacionalista (como la metafísica de la presencia y la ambición universalista de la teoría, desde el platonismo hasta Habermas). Pero, también, involucra un rechazo de toda tentación formalista (como la que se halla en gran parte de la investigación lingüística, desde la semiótica estructuralista y la sintaxis lógica neopositivista hasta la gramática universal chomskyana o la pragmática universal habermasiana). No en vano, Fish rechaza tanto los presupuestos teóricos (epistemológicos, lingüísticos y antropológicos) cuanto la propia pretensión de fundamentación teórica (el racionalismo transcontextual y la visión esencialista desvinculada) que, tradicionalmente, han bloqueado la cabal comprensión de nuestras prácticas interpretativas por haber eludido su eficacia local, su diferencia contextual, sus juegos persuasivos y sus autotransformaciones dinámicas. En primera instancia, y como consecuencia de su tentación teoricista, las teorías de corte fundacionalista y esencialista parten —según Fish - desde una visión epistemológica que reduce el ser de lo que hay a un conjunto de entes acontextuales, relacionalmente dispuestos y formalmente equivalentes entre sí. Por otra parte, para Fish, la epistemología fundacionalista presupone una verdad transcontextual y trascendente, y asume que es posible obtener un conocimiento tan desinteresado como capaz de superar las limitaciones de las perspectivas particulares; además, introduce un yo idéntico y homogéneo, un punto de vista tan autoconsciente como libre de parcialidad, y que puede aprehender y comunicar con total transparencia cierta realidad referencial independiente de los asuntos humanos (1992:169-170).

Desde este marco epistemológico y antropológico fundacionalista, Fish considera que se desarrolla toda una teoría de la interpretación que contrapone al sujeto-lector y al objeto-texto como entidades discretas e independientes, dando por hecho que entre ellos media cierta metodología descriptiva, con un vocabulario neutral, que permite darle forma discursiva a la relación entre lector y texto. Como si el sistema descriptivo que el lector introduce (con sus distinciones de géneros, categorías, cánones y estilos) pudiera contrastarse externamente con las estructuras de significado del texto, el cual operaría como principio regulador y de objetividad independiente a la que la descripción debería corresponder (1992:107-108). Ahora bien, para Fish, este fundacionalismo epistemológico e interpretativo se asocia a cierto formalismo el cual, más que una simple teoría del lenguaje, es, asimismo, una suma de presupuestos teóricos acerca del individuo, la racionalidad, la práctica y la 
política. A partir de la tesis lingüística de que existen significados fijos y claros, transcontextuales e independientes del uso lingüístico, el formalismo lleva a cabo una limitación y una subordinación de los deseos interpretativos y de las producciones de sentido, toda vez que consagra la codificación sistemática de lenguajes públicos impersonales, así como apela a un criterio de racionalidad trascendente, abstracto e independiente de los contextos particulares (1992:16-17).

Sin duda, las principales presuposiciones del formalismo se derivan — según Fish- de la creencia de que existe un significado literal (tan claro y transparente, como libre de contexto) que puede calcularse formalmente en función del significado de las partes constituyentes del texto. Por lo demás, Fish cree - siguiendo la estela del comentario derrideano de la pragmática austiniana - que esta tesis sobre el significado lingüístico se vincula a todo un conjunto de oposiciones relacionadas e interdependientes, que contrastan sistemáticamente el discurso pleno y un cierto discurso "huérfano". Se trata de oposiciones tales como: lenguaje literal, frente a lenguaje metafórico; discurso objetivo, frente al subjetivo; lenguaje científico, frente al expresivo; acto de habla locucionario, frente a ilocucionario; constatativo, frente a performativo, etc. (1992:64-65).

Como se puede apreciar, el avezado homo rethoricus que es Fish construye un abigarrado "muñeco de paja" para atacar todo aquello que contradiga la versión retórica de las prácticas interpretativas como juegos locales de persuasión. Semejante enemigo imaginario se forja por medio de una analogía negativa: así como el formalismo implica una concepción acontextual del orden de los significantes, del mismo modo, el fundacionalismo y el esencialismo introducen una perspectiva desvinculada y transcontextual de lo que hay (en ambos casos, no se asume la eficacia retórica local de nuestras prácticas interpretativas).

¿Quién se esconde detrás de la aparatosa carcasa de este "muñeco de paja”, en que convergen el fundacionalismo, el esencialismo y el formalismo? ¿La reificación del texto y del significante en la semiótica estructuralista o la falacia descriptiva de gran parte de la filosofía analítica del lenguaje? ¿Los intentos de establecer una sintaxis lógica (como en Carnap), una gramática universal (al estilo de Chomsky) o una pragmática universal (en la sintonía de Habermas)? ¿El platonismo y la metafísica de la presencia, o la teoría crítica? De todo un poco y nadie en específico. Al fin y al cabo, una caracterización negativa de todo lo que bloquea una apuesta interpretativa convencionalista y retórica no define concretamente ninguna posición intelectual efectivamente sostenida (aunque resulta obvia la alergia de Fish ante toda posición teórica crítica y universalista, como la que Habermas sostiene en su teoría de la acción comunicativa, que nuestro homo rethoricus insistentemente ataca). 
Además, no está claro que exista alguna convergencia posible (más allá de su presunto acontextualismo) entre tan disímiles posiciones teóricas que no excluyen relevantes divergencias entre sí, tal y como ocurre con el formalismo típico (que parece impugnar todo esencialismo metafísico, en nombre del orden de los significantes), el fundacionalismo estándar (que aparentemente rehúye el juego de las oposiciones formales diferenciales, apelando al fundamento) o la teoría crítica (que, básicamente, cuestiona toda reificación ya sea del código o del fundamento). Más explícitos, aunque no menos variopintos, resultan los aliados a quienes Fish apela para conjurar el espíritu de este curioso formalismo fundacionalista y esencialista, en nombre de un giro retórico: la deconstrucción derrideana, la pragmática austiniana de los actos de habla, el neo-pragmatismo de Rorty, el historicismo kuhniano, la crítica literaria de De Man, la nueva retórica de Perelman, el narrativismo de Hayden White, la estética de la recepción de Jauss e Iser, entre otros (1992:279-291;300-301).

\section{LA APUESTA HERMENÉUTICA DE FISH: CONVENCIONALISMO Y CONTEXTUALISMO}

Fish aporta una redescripción de nuestras prácticas interpretativas que, al asumir que los significados son siempre función del contexto intencional y de la perspectiva interpretativa, desbarata la dicotomía rígida entre el discurso referencialmente pleno $\mathrm{y}$, por otra parte, la figuración de un discurso "huérfano", referencialmente desasistido. Y es que — para Fish - la comprensión del significado se da siempre dentro de cierta trama intencional de intereses, propósitos y preocupaciones. De ese modo, para aprehender el significado no basta con conocer formalmente la referencia de los elementos lingüísticos aislados así como las reglas para combinarlos. Es preciso — según Fish - compartir una manera de pensar, una actividad general y una forma de vida, en las cuales ya estamos involucrados, a través de las metas, procedimientos y valores de que participamos (1982:303-304). Así, pues, tanto la interpretación del significado como la comunicación del sentido tienen lugar siempre en el seno de un sistema de inteligibilidad, o sea, desde nuestro involucramiento en contextos intencionales, así como en prácticas y asunciones institucionales sobreentendidas (1982:306). De hecho, no cabe concebir el significado al margen del contexto de pertenencia desde el cual ya siempre escuchamos los enunciados como significativos, y la discriminación entre los significados posibles de un enunciado será siempre situacional (1982:308-310). La construcción del sentido y la donación de significado ocurren —-según Fish— simultáneamente con la identificación del contexto y 
con la aprehensión de cierta estructura de comprensión, que se da como un trasfondo social de prácticas y propósitos compartidos (1982:313-318).

En suma, tanto la construcción del significado como nuestras prácticas interpretativas son — para Fish — propiedades comunitarias. De esa manera, el entendimiento compartido que sustenta la confianza de los interlocutores presupone la participación en un sistema de inteligibilidad institucional, del cual los intérpretes actúan como extensiones (1982:320-321). En todo caso, Fish considera que el contexto no es tanto un conjunto de aspectos empíricamente dados en el mundo, cuanto la constitución interpretativa de un mundo significativo a partir de asunciones y presupuestos siempre contextualizados. No en vano, los contextos son productores de la interpretación, pero, también, son productos de la interpretación (1992:82-83). Por eso, aclarar el significado no consiste — según Fish - en contrastar el texto con un contexto referencialmente dado e independiente, sino que pasa por producir una interpretación situacional desde cierto involucramiento confiado en nuestras prácticas interpretativas convencionales. De ahí que toda comunicación significativa implique el despliegue de un trabajo interpretativo incesante, centrado en la construcción situacional del significado y siempre expuesto a las inagotables contingencias de la interpretación. Y es que, en conclusión - para Fish - todo significado es el producto de una perspectiva interpretativa la que inevitablemente, descansa en otras construcciones y supuestos interpretativos sin que podamos establecer un fundamento último del sentido (1992:158-159).

El punto de vista que arraiga el significado en las comunidades interpretativas (en que estamos involucrados) parece proporcionar una adecuada comprensión del entendimiento compartido. De hecho, la autoridad interpretativa que nos vincula no podría recaer — según Fish - tan sólo en el texto (pues no habría divergencia interpretativa posible) ni tampoco únicamente en el lector individual (ya que no existiría un acuerdo viable entre los múltiples deseos interpretativos) (1992:105). En ese sentido, Fish asume y profundiza el giro hermenéutico al reconocer que, en cualquier campo de actividad humana, los significados y hechos, así como los procedimientos y valores, se construyen social y políticamente en la medida en que se elaboran interpretativamente a partir de presupuestos y propósitos compartidos, tan situacionales como históricamente contingentes (1992:277). No en vano, Fish asume una perspectiva marcadamente interpretativista y convencionalista conforme a la cual todos los significados y valores, así como nuestras razones y criterios, son un producto de los tiempos y un resultado de cierta historia interpretativa. De ese modo, nuestras prácticas interpretativas se atienen siempre a ciertas condiciones históricas y culturales contingentes, es decir, a 
las convenciones institucionales vigentes en las comunidades interpretativas a que pertenecemos (1992:206-207).

\section{LA IMPUGNACIÓN DE LA TEORÍA Y EL GIRO RETÓRICO}

Desde la perspectiva interpretativista y convencionalista que Fish adopta, no es posible obtener un punto de vista acontextual y desapegado ni, tampoco, podemos llevar a cabo una autorreflexión distanciada, al margen de los propios supuestos interpretativos situacionales. Y es que — según Fishnuestras prácticas significativas siempre resultan informadas por presupuestos interpretativos locales e históricamente contingentes. De ahí que la tentación teórica de alumbrar principios trascendentes y generales, independientemente de cualquier campo específico de actividad humana, constituya un sinsentido: no hay más principios que los contenidos y presupuestos locales de cada práctica específica (1992:28-29). Para Fish, no podemos disponer de principios neutrales que pretendan sostenerse como fundamentos esenciales y certezas universales, toda vez que las creencias específicas que sustentan nuestros deseos interpretativos están siempre especificadas situacionalmente y entrelazadas con las condiciones prácticas de determinadas comunidades interpretativas (2001:4).

Por otra parte — según Fish - quienes se auto-atribuyen principios neutrales no sólo eluden el pluralismo de las comunidades interpretativas, sino que, además, rebajan la relevancia práctico-política de tomar partido y comprometerse decididamente en la acción (2001:14). En ese sentido, Fish plantea que la teoría carece de consecuencias ya que no es posible remontarse a principios universales desde los cuales se pudieran deducir, programar y validar las prácticas históricamente contingentes. No en vano, todo presupuesto de nuestras prácticas se encuentra involucrado en una comprensión del contexto intencional, tan situacional como contingente, tan interpretativa como convencionalmente vigente (1992:45;41).

No existe, por tanto - para Fish — una relación universal y necesaria entre el posicionamiento teórico-epistemológico y las orientaciones prácticopolíticas. De hecho, no cabe establecer una relación teórica entre el surgimiento de una teoría y los cambios en las prácticas significativas (1992:40;129). Como Fish postula, las convicciones teóricas que se pueden sostener en una comunidad corresponden tan sólo a prolongaciones del sentido común que orienta los contextos prácticos compartidos. De ese modo, la teoría se perfila — según Fish — como una actividad más, tan situacional e históricamente condicionada como cualquier otra práctica (1992:127). Toda su eficacia radica en aportar una redescripción retóricamente persuasiva de 
prácticas ya vigentes, así como en la aceptación confiada de cierto léxico, dentro de una comunidad interpretativa históricamente situada (1992:43).

Por otra parte — para Fish— las prácticas teóricas de autodescripción de las actividades compartidas sólo establecen relaciones locales, contingentes e históricamente determinadas con respecto a la repercusión retórica que puedan tener en una comunidad histórica particular (1992:50-51). En suma, Fish considera que la ambición teórica de situarse en una perspectiva trascendente, al margen de las diversas esferas humanas de actividad, resulta insostenible: la teoría no produce transformaciones decisivas en las prácticas humanas (que se limita a redescribir) pero tampoco consigue llevar a cabo una autorreflexión crítica de nuestros presupuestos que nos permitiera emanciparnos de perspectivas parciales, haciéndonos autoconscientes de los fundamentos de posibilidad de nuestras prácticas (1992:127). En ese sentido, Fish cree que la autoconciencia reflexiva es tan irrelevante e inoperante como la propia ambición teórica. Y es que no hay actividad humana que sea independiente de la concienciación situacional de supuestos locales y contextos intencionales específicos; pero, precisamente por ello, no existe según Fish - una autoconciencia trascendente que se pueda ir ampliando desde una perspectiva tan universal como privilegiada, al margen de los ámbitos circunstanciales de actividad o más allá de la historicidad y lingüisticidad de nuestra condición hermenéutica (1992:236-238).

Al reconocer que tanto la reflexión teórica como la autoconciencia crítica corresponden únicamente a estrategias retóricas para la redescripción persuasiva de nuestras prácticas, Fish pone en primer plano el componente retórico de toda construcción discursiva y de toda práctica interpretativa. Así, pues, Fish cree que con el giro interpretativo cobra protagonismo la retórica, en tanto arte de redescribir persuasivamente los presupuestos locales y nuestras convicciones contingentes (1992:271). A contrapelo de la tradición antirretórica asociada al fundacionalismo y al esencialismo, Fish asume que tan sólo hay reinterpretaciones de reinterpretaciones que se aceptan en las comunidades interpretativas debido, solamente, a su eficacia persuasiva y, por tanto, de modo contingente e históricamente situado. Desde esta posición retórica, los argumentos que parecen racionalmente evidentes, acontextuales y trascendentes, se presentan únicamente como discursos localmente persuasivos, que - para Fish - tienen peso argumentativo porque se han vuelto convenciones y rutinas institucionales en una situación histórica determinada (1992:174-175).

En suma, reconocer la retoricidad de todo discurso implica aceptar el carácter mediado y socialmente construido de cualquier sentido y verdad. De ese modo — según Fish- cobra protagonismo el homo rethoricus, es decir, la condición de quien asume el sentido retórico (persuasivo y escénico, 
convencional e interpretativo) de todas nuestras prácticas y posiciones interpretativas. $\mathrm{Y}$ es que Fish insiste en que no hay perspectivas privilegiadas, universales y desapegadas, desde las cuales excluir algunas estrategias e intervenciones interpretativas como “meramente retóricas” (1992:274-277-288).

CONTINUIDAD Y DISCONTINUIDAD CON LA HERMENÉUTICA FILOSÓFICA

Sin duda, la redescripción de nuestras prácticas interpretativas que Fish realiza, por muy post-filosófica y retórica que pretenda ser, hunde sus raíces en la hermenéutica filosófica. De hecho, la apuesta interpretativa de Fish parece reconocer implícitamente algunas caracterizaciones filosóficas de la experiencia hermenéutica: ya sea que entendamos ésta como cierto diálogo pensante en que el intérprete del mensaje proviene ya del mensaje mismo y corresponde a la destinación del sentido (Heidegger, 1987:136-137); ya sea que la concibamos como autocomprensión de la facticidad, lingüisticidad e historicidad de la conversación que somos (Gadamer, 2004:217-224); ya sea que la pensemos como comprensión reflexiva de la dialéctica entre acontecimiento y sentido, en el discurso y en los mundos textuales que construimos (Ricoeur, 2000:96-98).

Por lo demás, son múltiples los puntos de arraigo en que la hermenéutica literaria de Fish entronca con el giro hermenéutico de la filosofía: el marcado malestar ante el metodologismo formalista y ante las pretensiones de una autoconciencia teórica tan desapegada como objetivadora (Gadamer, 2004:54-55); la crítica del fundacionalismo y de toda autocerteza metafísica que pretenda suministrar acceso a una verdad absoluta y a una presencia plena (Grondin, 1999:198-199); la comprensión del sentido discursivo a partir de los presupuestos y nexos intencionales de nuestro ser en el mundo (Heidegger, 1998:34); la asunción del carácter interpretativo, dialógico y compartido de toda experiencia (Gadamer, 2004:148-152); la vinculación de nuestras creencias con trasfondos intencionales y sentidos transmitidos tradicionalmente (Gadamer, 2004:114-115); e, incluso, la aceptación del componente retórico, discursivo y conversacional, que se patentiza en un entendimiento interhumano no susceptible de demostración lógica concluyente (Gadamer, 2004:275-281).

Sin embargo, en cierto sentido, la hermenéutica literaria de Fish se distancia de la hermenéutica filosófica cuando se trata de concebir el modo de validación de nuestras prácticas interpretativas. Entonces, lo que (para Fish) sostiene la validez y propiedad de nuestra experiencia interpretativa ya no es tanto la apertura desocultadora del ser y el acontecimiento apropiador del sentido, ni tampoco la patentización dialógica de la cosa misma y la fusión de 
los horizontes de sentido (Heidegger, 1998:44;239-246; Gadamer, 2004:5462) sino, más bien, tan sólo la aprobación institucional, así como la sanción obtenida desde las prácticas profesionales y los hábitos operacionales en una comunidad interpretativa determinada. De ese modo, la hermenéutica literaria de Fish parece dejar impensadas las vías de validación de esa autoridad sancionadora que una comunidad interpretativa se arroga en sus hábitos profesionales. A diferencia de lo que ocurre en la hermenéutica filosófica, Fish se limita a tematizar la validación de la autoridad interpretativa desde una perspectiva tan convencionalista y pragmatista como desfondada, y tan antifundacionalista como profesionalista e institucionalista (Ferraris, 2000: 345). Esta divergencia en las modalidades de validación de nuestras prácticas interpretativas puede asociarse a las diferentes maneras como la hermenéutica filosófica y la hermenéutica literaria de Fish entienden la relación entre comprensión e interpretación.

En la hermenéutica filosófica hay cierta primacía del trasfondo originario de la comprensión, entendido como la facticidad de la proyección de posibilidades de nuestro ser en el mundo y como la constitución lingüística e histórica del sentido conversacionalmente compartido. Así, pues, la interpretación se limita a explicitar cierta precomprensión mundana del sentido transmitido en que ya estamos involucrados, y se autocancela en lo comprendido cuando el sentido transmitido y la cosa misma encuentran la palabra adecuada (Heidegger, 1998:32; Gadamer, 2003:566-567). En la hermenéutica literaria de Fish, parece predominar el momento interpretativo $-\mathrm{o}$ sea, la redescripción convencionalista de las construcciones del sentido- a través de un movimiento vertiginoso de reinterpretación de las reinterpretaciones, que desfonda toda precomprensión de un horizonte de sentido. Así, pues, en la producción y atribución de significados sólo rigen, en última instancia, los contextos intencionales convencionalmente instituidos en las prácticas interpretativas profesionales e intramundanas. Por lo demás, aunque exista una indudable afinidad entre hermenéutica y retórica (que Fish reivindica con insistencia) la hermenéutica desborda el mero arte de la persuasión y del entendimiento estratégicamente inducido, toda vez que supone la apertura conversacional a la alteridad, el encuentro con el otro y la fusión de los horizontes de sentido compartidos a través de nuestro ser en común (Gadamer, 2004:117).

\section{LAS COMUNIDADES INTERPRETATIVAS EN LA HERMENÉUTICA LITERA-} RIA DE FISH

La acuñación conceptual de cierta "comunidad interpretativa” juega un papel decisivo en la hermenéutica literaria de Fish. Pero ¿Qué entiende Fish 
por “comunidad interpretativa? ¿De qué manera se relacionan las comunidades interpretativas con nuestras creencias, con los individuos, con las instituciones y con el cambio? En primera instancia — para Fish- la comunidad interpretativa no consiste tanto en un grupo de individuos que comparte cierto punto de vista, cuanto en una perspectiva y forma de organizar la vida que "comparte individuos". De hecho, las dimensiones estimativas y las categorías de comprensión compartidas (así como los procedimientos probatorios instituidos) conforman la conciencia de los intérpretes individuales quienes devienen, así, miembros involucrados y extensiones de una empresa comunitaria (1992:105-106). De ese modo — según Fish - los intérpretes individuales son constituidos por la comunidad interpretativa como los propios textos que las comunidades interpretativas construyen y elaboran. Por otra parte, Fish considera que las comunidades interpretativas conforman un emplazamiento en que nuestros deseos interpretativos encuentran limitaciones prácticas y frenos institucionales. Todo intérprete sigue, pues, caminos delimitados por los conjuntos de prácticas vigentes, así como por los propósitos y construcciones institucionales compartidos local e históricamente (1992:26-27). Y es que sólo dentro de los límites y de los ámbitos institucionalmente articulados resulta concebible - para Fish - la práctica interpretativa y el entendimiento compartido. Sólo en la medida en que existe un trasfondo institucional que prefigura las posibilidades de nuestra forma de vida podemos llevar a cabo acciones significativas y dar curso a otros deseos interpretativos, siempre ya institucionalmente insinuados (1992:197-199;244).

En consecuencia, Fish cree que nuestras prácticas interpretativas se limitan a prolongar redes compartidas de presupuestos y creencias, propósitos y procedimientos que mantenemos con firmeza (aunque resulten históricamente contingentes) toda vez que nos conforman y constituyen (1992:207). No se trata, únicamente, de que nuestras creencias siempre estén entrelazadas en entramados de presupuestos y escenarios organizativos (con distintas prioridades e intereses) de manera que no se puede hablar de propósitos o razones no institucionales. De hecho, no existen razones ni deseos interpretativos al margen de los contextos intencionales y presupuestos de comprensión en los cuales ya estamos comprometidos dentro de nuestra actividad cotidiana socialmente organizada (1992:202).

Además, para Fish, los códigos que organizan nuestra experiencia contingente, permitiéndonos relacionar los aspectos del mundo con los intereses y propósitos de una comunidad interpretativa, no son estructuras o mecanismos estáticos sino que, más bien, constituyen proyectos dinámicos y flexibles que se van modificando a través de las prácticas que informan, así como mediante los supuestos que elaboran (1992:119-121). En ese sentido, 
las comunidades interpretativas (esos conjuntos de prácticas institucionales, códigos compartidos y redes de creencias que nos constituyen) operan como auténticos motores del cambio, ya que, aunque parezcan homogéneas por el horizonte compartido de su propósito general, resultan heterogéneas y cambiantes por la diversidad de dinámicas que se despliegan en su seno.

No en vano - según Fish- las prácticas de las comunidades interpretativas se están autotransformando continuamente, en el mismo momento en que las contingencias emergentes resultan asimiladas a la historia y propósitos compartidos (1992:117;122-123). Como cualquier actividad socialmente organizada, también la práctica interpretativa y la creencia compartida no cesan de autotransformarse. Para Fish, no pueden dejar de reinterpretar sus supuestos y deseos interpretativos, según se van absorbiendo las contingencias situacionales tanto en la trama estructural de presupuestos como en la continuidad histórica de los deseos interpretativos (1992:250). Por lo demás, Fish considera que no somos miembros de una sola comunidad interpretativa cerrada sino que participamos en diferentes contextos intencionales, asociados situacionalmente a comunidades interpretativas diversas. De ese modo, hemos de lidiar con diferentes exigencias y roles interpretativos. En fin —para Fish - el arraigo hermenéutico en comunidades interpretativas supone una condición fracturada e inestable (1992:54-57) y, sin embargo, los compromisos profesionales y entramados institucionales que “comparten individuos” no pueden ser rebasados o trascendidos críticamente.

En ese sentido, Fish domestica los conflictos de interpretaciones y la fractura de las comunidades interpretativas, presentando las contradicciones inmanentes a los marcos socio-históricos como si tan sólo se tratara de una heterogeneidad en el reparto de los roles profesionales o de cierta diferencia de perspectivas institucionales que resultan tan inconmensurables como equivalentes. En última instancia, da la impresión que la autotransformación de las comunidades interpretativas, que Fish consagra retóricamente, resulta impermeable a toda impugnación o contestación del principio de organización y de los frenos institucionales que guían el cambio en las comunidades interpretativas. De ese modo, los compromisos profesionales y entramados organizativos resultan tan incontestables e ineluctables - en tanto marco de la autotransformación institucional- como inapelables y opacos son los sistemas de creencias que guían pre-reflexivamente la actividad interpretativa y la persuasión retórica local (Eagleton, 2005:219-220).

\section{LA INTERPRETACIÓN DE LA COMUNIDAD INTERPRETATIVA EN LA HERMENÉUTICA FILOSÓFICA}

En gran medida, si la posición de la hermenéutica literaria de Fish resulta fronteriza con respecto a la hermenéutica filosófica es, precisamente, 
por el modo como concibe la comunidad interpretativa, a saber: como un entramado institucional y como un conjunto de contextos intencionales, convencionalmente construidos y habitualmente reinterpretados en nuestras prácticas profesionales (Fish, 1992:123). En ese sentido, esta visión convencionalista, profesionalista e institucionalista de las comunidades interpretativas aparece desarraigada de todo trasfondo ontológico, así como está desvinculada de una comprensión cabal de nuestro ser en común y del sentido constituyente de la comunidad.

Ciertamente, como contrapartida del planteamiento de Fish, no existe una única versión de la comunidad constituyente que la hermenéutica filosófica presupone. En todo caso, fue preciso poner de manifiesto el trasfondo ontológico del ser en común y de la comunidad constituyente para que se pudiera desplazar la encrucijada en que se hallaban atrapadas la hermenéutica técnica y la metodología hermenéutica, a la hora de concebir la comunidad interpretativa. Y es que la concepción de esa comunidad hermenéutica que subyace a toda comprensión del sentido compartido oscilaba fatalmente entre la congenialidad de los espíritus (como en el caso de Schleiermacher) o bien la expresión vital del espíritu objetivo en las obras, instituciones y sistemas culturales (como en el caso de Dilthey) (Gadamer, 2004:100-103; Ricoeur, 2000:73-82).

Desde luego, cuando Heidegger se hace cargo del sentido existencial del ser en común, no se limita a consagrar la identificación intersubjetiva ni, tampoco, las comunidades profesionales y las convenciones institucionales (tan relevantes para Fish) en virtud de las cuales los sujetos coexisten intramundanamente. De hecho - para Heidegger - tanto el coexistir intramundano como las convenciones intersubjetivas se arraigan en el trasfondo de cierto convivir comprensor, es decir, en la comprensión originaria del coestar (del ser con y por mor de los otros) así como en la solicitud preocupada. Sólo a partir de este trasfondo originario de convivencia y solicitud se abre la posibilidad de instituir relaciones intramundanas convencionales y de establecer un reconocimiento intersubjetivo (Heidegger, 1998:26). Además, en la hermenéutica heideggeriana de la facticidad, el sentido de la comunidad constituyente pasa por la repetición destinal precursora de un legado de posibilidades y por la resuelta destinación histórico-epocal, pero no consiste en el impropio acostumbramiento convencional a las prácticas institucionales y a los hábitos profesionales consuetudinarios (que Fish consideraría un presupuesto de toda interpretación viable, 1998:75). Por otra parte, también en la hermenéutica filosófica de Gadamer se insiste en el arraigo ontológico de la comunidad constituyente, toda vez que se enfatiza la constitución lingüística de nuestro ser en común, así como la movilidad histórica de los horizontes de sentido de nuestro convivir. La comunidad hermenéutica es — para Gadamer- 
encuentro conversacional y fusión de horizontes, desde los sentidos tradicionalmente transmitidos que compartimos, más que un conjunto de convenciones institucionales sujetas a disposición estratégica, como Fish parece sostener (2004:205-208).

Incluso, entre las versiones de una cierta hermenéutica postmetafísica que podría parecer más próxima a la hermenéutica literaria de Fish (como es el caso de la hermenéutica neopragmatista de Rorty o de la hermenéutica nihilista de Vattimo) la comunidad interpretativa no es tan sólo un repertorio de prácticas institucionales convencionalmente compartidas en la ocupación profesional, como ocurre en Fish. Por más que - en la hermenéutica postmetafísica - se cuestione toda hipóstasis ontoteológica de la comunidad en tanto fusión transparente y presencia plena del sentido, en tanto transposición identificadora basada en una naturaleza humana común, o en tanto anticipación contrafáctica de una situación ideal de comunicación (Vattimo, 1991: 205-208). Sin embargo — a diferencia de Fish - la comunidad interpretativa no consiste únicamente en un constructo institucional autorreferente. Más bien, ella se constituye en virtud del mismo movimiento con que se destituye, disloca y distorsiona: tanto mediante la redescripción metafórica cuanto a través de la rememoración irónica de los léxicos y sentidos tradicionalmente transmitidos (Vattimo, 1991:28-35). Pero lo más decisivo es que la comunidad hermenéutica postmetafísica requiere de cierta "solidaridad" (entendida como identificación imaginativa con los detalles de las vidas ajenas y con la humillación de los otros) o, bien de cierta pietas (concebida como atención devota a las huellas de vida de nuestros semejantes y amor al prójimo) que, si bien no tienen un fundamento necesario, introducen un margen de exposición a lo otro y de alteridad constituyente en la trama de nuestro ser en común (Rorty, 1991:207-210).

En fin, la comunidad interpretativa que Fish consagra (como marco institucional de toda interpretación) se aleja del sentido de comunidad constituyente que la hermenéutica ha planteado como trasfondo de toda comprensión. La de Fish es una comunidad constituida e institucionalmente autorreferente que no sólo desconoce la alteridad constituyente y la exterioridad compareciente de nuestras prácticas interpretativas sino que, además, bloquea la apertura ontológica de sentidos de nuestro ser en el mundo (ya que Fish privilegia la eficacia local de las retóricas institucionales) así como frena el autocuestionamiento crítico de las fracturas, contradicciones internas y conflictos de interpretaciones que desbaratan, siempre, cualquier clausura institucional de la comunidad. 
Comunidades interpretativas. Perspectivas de la hermenéutica literaria

\section{CONCLUSIÓN. MÁS ALLÁ DEL CONVENCIONALISMO E INSTITUCIO- NALISMO DE FISH: LOS MÁRGENES DE LA KOINÉ HERMENÉUTICA}

Como pone de manifiesto la contemporánea hermenéutica de la comunidad, la experiencia de la comunidad interpretativa no se deja reducir al dominio de la obra objetivable y producible ni a la autocomplacencia de un conjunto de artefactos institucionales o de un repertorio de disposiciones estratégicas profesionales (tal y como podría pensarse desde el convencionallismo retórico e institucional de Fish). Pensar la comunidad interpretativa no puede consistir tan sólo en la consagración de la opacidad e inercia de las prácticas institucionales y profesionales (por muy desfondadas que —como ocurre en el enfoque de Fish- se las considere).

En ese sentido $-\mathrm{y}$ a contrapelo de la comprensión de la comunidad interpretativa en Fish - Jean-Luc Nancy recuerda, mejor que nadie, que la comunidad comienza donde termina la obra institucional y profesional

Por eso la comunidad no puede depender del dominio de la obra. No se la produce, se hace la experiencia de ella (o su experiencia nos hace) como experiencia de la finitud. La comunidad como obra, o la comunidad gracias a las obras, supondría que el ser en común, como tal, sea objetivable y producible (en lugares, personas, edificios, discursos, instituciones, símbolos: en una palabra, en sujetos). (...) La comunidad tiene lugar en lo que Blanchot denominó el desobramiento. Más acá o más allá de la obra, eso que se retira de la obra, eso que ya no tiene nada que ver ni con la producción, ni con la consumación, sino que tropieza con la interrupción, la fragmentación, el suspenso. La comunidad está hecha de la interrupción de las singularidades, o del suspenso que son los seres singulares. Ella no es obra, ni siquiera una operación de los seres singulares: porque ella es simplemente su ser -su ser suspendido sobre su límite. La comunicación es el desobramiento de la obra social, económica, técnica, institucional (2000:61).

Por lo demás — como, tal vez el propio Fish hubiera asumido- la comunidad interpretativa no ha de ser concebida, tampoco, en tanto que una propiedad de los sujetos (una determinación o predicado que los califique como parte del mismo conjunto) o como un ámbito de pertenencia intersubjetiva o de intimidad comunicativa, ni como una sustancia producida por la comunión orgánica o la fusión en una unidad sin fisuras (Nancy, 2000:30-31; Esposito, 2003:21-22). La comunidad interpretativa no constituye una posesión que se pueda concebir bajo la figura de lo propio (como un sujeto en sumo grado). Más bien, hay que pensarla como aquella deuda a partir de la cual somos expropiados y como aquel extrañamiento entregado que nos 
expone - en tanto que singulares - tanto a la interpelación de los otros como al reparto del estar en común (2003:30-32). Y es que únicamente haciéndonos cargo de la exterioridad y alteridad que marcan nuestro ser en común, únicamente exponiéndonos a los modos de comparecencia y rememoración que abren una experiencia compartida -e interrumpen la clausura de toda identidad o propiedad comunitaria - podremos lograr una comprensión involucrada de esa comunidad constituyente que la koiné hermenéutica ha puesto en el centro de su meditación (y que resulta marcadamente distinta de la comunidad institucionalmente constituida que Fish teoriza). Tal vez podamos invocar, de algún modo, ese reparto de las voces singulares, esa articulación e inscripción de nuestro estar en común, esa exposición limítrofe que interrumpe el habla fundacional y permite comunicarnos un sentido en común, siempre ya distribuido y diferido. Semejante experiencia de la inscripción singular, del reparto de las voces, de la diferencia del sentido, así como del habla interrumpida, fragmentada y plural constituye, quizás, la aventura que nos invita a realizar la experiencia literaria cuando asume la ausencia de obra (Blanchot, 1970:622-624; Nancy, 2000:123-136). En fin, la comunidad hermenéutica que otrora se congregó en torno a ciertas técnicas o metodologías de exégesis textual, o que trató de arraigarse ontológicamente en un propio coestar en el mundo (y que Fish ha intentado reducir a un trasfondo institucional de compromisos profesionales) resulta actualmente convocada en los márgenes de la inscripción de nuestro estar en común, allá donde se patentiza la exterioridad del reparto de las voces singulares.

C/ Volcán Corcovado 5036, Puerto Montt (Chile)* juannelly@surnet.cl 
Comunidades interpretativas. Perspectivas de la hermenéutica literaria

\section{BIBLIOGRAFÍA}

BLANCHOT, Maurice. El diálogo inconcluso. Caracas: Monte Ávila, 1970.

EAGLETON, Terry. Ideología. Una introducción. Barcelona: Paidós, 2005.

ESPOSITO, Roberto. Communitas: origen y destino de la comunidad. Buenos Aires: Amorrortu, 2003.

FERRARIS, Maurizio. Historia de la hermenéutica. Madrid: Akal, 2000.

FISH, Stanley. The trouble with principle. Massachusetts: Harvard University Press, 2001.

------- Práctica sin teoría: retórica y cambio en la vida institucional. Barcelona: Destino, 1992.

------ Is there a text in this class? The authority of interpretative communities. Massachusetts: Harvard University Press, 1982.

GADAMER, Hans-Georg. Verdad y método II. Salamanca: Sígueme, 2004. - Verdad y método I. Salamanca: Sígueme, 2003.

GRONDIN, Jean. Introducción a la hermenéutica filosófica. Barcelona: Herder, 1999.

HEIDEGGER, Martin. Ser y tiempo. Santiago: Universitaria, 1998.

------ De camino al habla. Barcelona: Serbal, 1987.

NANCY, Jean-Luc. La comunidad inoperante. Santiago: LOM, 2001.

RICOEUR, Paul. Del texto a la acción. Buenos Aires: F. C. E., 2000.

RORTY, Richard. Contingencia, ironía y solidaridad. Barcelona: Paidós, 1991.

VATTIMO, Gianni. Ética de la interpretación. Barcelona: Paidós, 1991. 